\title{
ENSAIO
}

\section{O CORPO NA CONTEMPORANEIDADE: POSSÍVEIS CAMINHOS DA EDUCAÇÃO FÍSICA NO ENSINO MÉDIO}

\author{
BODY CONTEMPORANEITY: POSSIBLE WAIS OF PHYSICAL \\ EDUCATION IN SECONDARY EDUCATION
}

\section{EL CUERPO EN LA CONTEMPORANEIDAD: POSSIBLES CAMINOS DE LA EDUCACIÓN FÍSICA EN LA ENSEÑANZA MEDIA}

LARISSA Beraldo KaWASHima Universidade Federal de Mato Grosso

Evando Carlos Moreira Universidade Federal de Mato Grosso

\begin{abstract}
Resumo Este ensaio tem o objetivo de tematizar o corpo nas aulas de Educação Física do ensino médio. Para tanto, abordaremos a perspectiva de corpo a partir de David Le Breton e Zygmunt Bauman e experiências possíveis de diálogo entre corpo, saúde, estética, nutrição e esporte. As possibilidades de tematizar o corpo nas aulas de Educação Física do ensino médio sugeridas ilustram como o contexto escolar pode se apropriar dessas discussões e conhecimentos, conduzindo os alunos a outras reflexões e análises, de maneira crítica e consciente.
\end{abstract}

Palavras-chave: Corpo; Ensino; Ensino Médio.

Abstract This test is intended to relate the body in the classes of Physical Education oh high school. They will be presented to the body perspective from authors David Le Breton and Zygmunt Bauman, and possible experiments in which the body interacts with health, beauty, nutrition and sport. The possibilities of foregrounding the body in Physical Education suggested high school illustrate how the school context can take ownership of these discussions and knowledge, leading students to further reflection and analysis, critical and conscious way.

Key-words: Body; Education; High SchoOl. 
RESUMEn Este ensayo tiene el objetivo de relacionar el cuerpo en las clases de Educación Física de la enseñanza media. Se presentarán la perspectiva del cuerpo a partir de David Le Breton y Zygmunt Bauman, además de experiencias posibles en que el cuerpo dialoga con la salud, estética, nutrición y deporte. Las posibilidades de tematizar el cuerpo en las clases de Educación Física de la enseñanza media sugeridas ilustran como el contexto escolar puede apropiarse de estas discusiones y conocimientos, conduciendo los alumnos a otras reflexiones y análisis, de manera crítica y consciente.

Palabras clave: Cuerpo; Enseñanza; Enseñanza Média.

\section{INTRODUÇÃo}

Refletir sobre questões recorrentes da Educação Física no ensino médio, como falta de interesse dos alunos, precarização dessa fase de ensino ou o esporte como conteúdo hegemônico, parecem-nos triviais, recorrentes, já que o ensino médio e o componente curricular Educação Física vivem em "estado de crise". Fensterseifer e González (2013) partem desta ideia de Hannah Arendt do "estado de crise", ou seja, quando o sentido de algo não é mais óbvio, para discutir os desafios da legitimação da Educação Física na escola republicana.

A história da Educação Física está intrinsecamente ligada à história do corpo, esta por sua vez à história da humanidade. Não podemos negar esse conhecimento nem a nós mesmos, nem aos nossos alunos.

Se a Educação Física lida com o movimento humano nas suas diferentes manifestações, nada mais importante do que compreender o corpo, base e alicerce do movimento, que ao se relacionar com a cultura cria suas diferentes formas de movimento. Para Neira (2007, p. 14), o corpo é entendido como suporte de linguagem que manifesta a cultura em que está inserido, ou seja, "ao se movimentarem homens e mulheres expressam intencionalidades, comunicam e veiculam modos de ser, pensar e agir característicos, ou seja, culturalmente impressos em seus corpos".

Nesse sentido, entende-se o corpo como um suporte textual onde se inscrevem a história e a trajetória dos homens e da cultura, ou seja, se compreende o corpo como "texto da cultura" e os gestos os "textos do corpo" (NEIRA, 2007).

Segundo Neira (2009, p. 72):

A Educação Física deve garantir ao educando o acesso à cultura corporal historicamente acumulada por meio da experimentação das variadas formas com as quais ela se apresenta na sociedade; proporcionar o espaço para análise e interpretação dos motivos que levaram determinados conhecimentos acerca das práticas corporais à atual condição privilegiada ou não, como também refletir sobre os saberes alusivos à corporeidade veiculados pelos meios de comunicação de massa e aqueles produzidos e reproduzidos pelos grupos culturais historicamente desprivilegiados $[\ldots]$.

Moreira e Grunennvaldt (2016) alertam para o objetivo da Educação Física na escola (e, por conseguinte, no Ensino Médio) ser o mesmo objetivo da própria escola, contri-

Comunicações | Piracicaba | v. 25 | n. 3 | p. 325-339| set.-dez. 2018 
buindo para o processo de formação humana e garantindo que os alunos sejam leitores críticos da sociedade. Nesse caso, cabe à Educação Física no Ensino Médio dar condições para que os estudantes conheçam profundamente o patrimônio cultural relacionado às mais diferentes manifestações da cultura de movimento. Além disso, uma Educação Física que considere apenas a prática esportiva não conseguiria contemplar os objetivos da escola, sendo necessária uma organização curricular com conteúdos sistematizados e integrados à proposta pedagógica da escola.

É preciso reconhecer que a atividade educacional profissional e institucionalizada na escola pressupõe o ensino, ou seja, a disseminação de um conteúdo específico dentro de um contexto hierarquizado pela posse de determinados conhecimentos e mesmo de um papel social muito diferenciado entre professor e alunos. Assim, o papel da escola é conservar e disseminar os conteúdos culturais de uma civilização ou nação, além de preparar a passagem do privado (família) para o público (política/cidadania), viabilizando sua inserção e ação no mundo, por meio da qualificação da capacidade de interlocução (CARVALHO, 1996 apud GONZÁLEZ; FENSTERSEIFER, 2009).

Após estas considerações iniciais questionamos: é possível tematizar o corpo, relacionando-o aos conceitos de Bauman e Le Breton, e produzir conhecimentos para as aulas de Educação Física do ensino médio?

Para tanto, estabelecemos como objetivo deste ensaio tematizar o corpo nas aulas de Educação Física do ensino médio, com vistas a fomentar e ampliar os conhecimentos dos alunos sobre essa temática.

\section{O CORPO E A JUVENTUDE}

Antes de tratarmos do corpo na contemporaneidade, faz necessário esclarecer a opção em tratar essa temática a partir dos referenciais teóricos do sociólogo e antropólogo francês David Le Breton e do sociólogo polonês Zygmunt Bauman, que necessariamente dialogam entre si, mas apresentam elementos importantes para entendermos o corpo na sociedade contemporânea. De um lado, David Le Breton debate o corpo como algo que o ser humano busca transformar, reconstruir, refazer, sempre, e em diversas circunstâncias, transformando-o em algo transitório. De outro lado, Zygmunt Bauman entende que o corpo é fruto de uma sociedade que produz anseios, e necessidades efêmeras, sem sentido, tornando-o escravo das novidades.

Os alunos do ensino médio são, em sua maioria, jovens, que atribuem maior importância à possibilidade de socialização com outros jovens, o que, às vezes, parece falta de interesse deles pela escola. Além disso, o jovem do Ensino Médio vive as incertezas típicas de sua idade, privilegiando o imediatismo, o presente, características apontadas por Bauman (2007) ao conceituar a sociedade líquida. Assim, a formação dos grupos sociais é parte importante do processo de formação desses jovens e a compreensão desse processo pode nos sensibilizar a dialogar com esses jovens em nossas aulas. Nesse sentido, Bauman (2005) 
em seu livro "Identidade", responde a pergunta de Benedetto Vecchi sobre sua comparação da biografia com um quebra-cabeça, dizendo que "é preciso compor sua identidade pessoal da mesma forma como se compõe uma figura com as peças de um quebra-cabeça, mas só se pode comparar a biografia com um quebra-cabeça incompleto, ao qual faltem muitas peças" (BAUMAN, 2005, p. 54). O quebra-cabeça da loja vem completo e tem uma forma final, mas nossas identidades não. Não se começa pela imagem final, mas por uma série de peças já obtidas ou que pareçam valer a pena ter, e então se tenta descobrir como é possível agrupá-las e reagrupá-las para montar a imagem. A principal preocupação não é juntar as peças e formar um todo coeso, firmemente fixado e solidamente construído em relação à identidade, pois seria uma limitação da liberdade de escolha - uma receita de inflexibilidade. A identidade só nos é revelada como algo a ser inventado, e não descoberto, como alvo de um esforço, um objetivo.

A identidade dos jovens estudantes do Ensino Médio também passa por um processo de constante construção, e transformação, assim como a identificação que fazem de seus corpos, o que, segundo Le Breton (2003), se trata de um objeto imperfeito, um rascunho a ser corrigido. Portanto, tanto o corpo quanto a identidade dos jovens são inacabadas e isso acaba por influenciar a relação professor-aluno durante as aulas de Educação Física, bem como os conteúdos que são compartilhados aos mesmos.

\subsection{O corpo em David Le Breton}

O conceito de corpo para David Le Breton foi composto a partir de três obras: "Adeus ao corpo: antropologia e sociedade" (2003); "Condutas de risco: dos jogos de morte aos jogos de viver" (2009) e "Antropologia do corpo e modernidade" (2012).

Para Le Breton (2003), o corpo se transforma cada vez mais em máquina, sem sujeitos nem afetos. Em sua concepção, o corpo tem sido, equivocadamente, compreendido como um objeto imperfeito, um rascunho a ser corrigido, ou seja, não se trata mais de um corpo, mas de um acumulado de órgãos colados em algo que se denomina corpo.

Le Breton (2003, p. 15) menciona o ódio ao corpo traduzido pelas diversas doutrinas gnósticas, que o tornam uma indignidade sem remédio.

O corpo é o pecado original, a mácula de uma humanidade da qual alguns lamentam que ela não seja de imediato de proveniência tecnológica. O corpo é um membro supranumerário, seria necessário suprimi-lo.

A religiosidade é um dado estrutural do extremo contemporâneo que faz do corpo um lugar a ser eliminado ou modificado. Um corpo perfeito seria de certa forma livre do próprio corpo.

Para Le Breton (2003), no discurso científico, o corpo é normalmente colocado como um alter ego consagrado ao rancor dos cientistas. Subtraído do homem que encarna à maneira de um objeto, esvaziado de qualquer valor. O corpo é declinado em peças isoladas, é esmigalhado. $\mathrm{O}$ corpo encarna a parte ruim, o rascunho a ser corrigido. Muitos autores 
veem com júbilo chegar o momento abençoado do tempo "pós-biológico" ou "pós-evolucionista", em suma, do tempo do fim do corpo, este sendo um artefato passível de ser danificado pela história humana, e que a genética, a robótica ou a informática devem conseguir reformar ou eliminar. "Uma fantasia implícita, informulável e um contexto de pensamento leigo, é subjacente - a de abolir o corpo, eliminá-lo pura e simplesmente, substituindo-o por uma máquina da mais alta perfeição" (LE BRETON, 2003, p. 17).

Essa condição pode ser observada quando pensamos em Descartes, que desliga a inteligência do homem de carne, no qual o corpo não passa de uma presença, vemos a premissa da tendência "dura" da Inteligência Artificial. Nela, o homem não passa de sua inteligência, o corpo nada é exceto um entrave. A biotecnologia ou a medicina moderna privilegiam o mecanismo corporal, o arranjo sutil de um organismo percebido como uma coleção de órgãos e funções potencialmente substituíveis. Não se compara a máquina ao corpo, mas o corpo à máquina (LE BRETON, 2003).

Essa ambiguidade, herdada dos séculos XVI e XVII, ilustradas pelos momentos de Vesalius (1543) ou Descartes (1637) não foram abandonadas. O modelo dualista persiste e acompanha a liberação do corpo. Mas esse dualismo, para Le Breton (2012), é mais que a ensomatose (queda do corpo), mas a chance do corpo, a carne, via de salvação. O corpo é a morada do homem, seu rosto; momento de dualidade em uma vertente desagradável (doença, velhice, deficiência, fadiga) ou em uma vertente agradável (prazer, ternura, sensualidade), oferecendo a sensação ao ator de que seu corpo lhe escapa, de que excede aquilo que ele é. O dualismo moderno não esquarteja a alma (ou espírito) e o corpo, ele é mais insólito, mais indeterminado. Avança mascarado, temperado, sob diversas formas, mas todas repousam na visão dual do homem. O dualismo contemporâneo distingue o homem de seu corpo.

\footnotetext{
Esse imaginário do corpo segue fielmente e (sócio) logicamente o processo de individuação que marca as sociedades ocidentais de maneira acelerada desde o fim dos anos 1960: investimento da esfera privada, preocupação com o eu, multiplicação dos modos de vida, atomização dos atores, obsolescência rápida das referências e dos valores, indeterminação. Um novo tempo do individualismo ocidental vem ao mundo e modifica em profundidade as relações tradicionais em relação ao corpo (LE BRETON, 2012, p. 242).
}

Nos séculos passados, certamente, nunca o homem utilizou tão pouco seu corpo, sua mobilidade, sua resistência como hoje nas sociedades ocidentais. O consumo nervoso (estresse) substituiu o consumo físico. Os recursos musculares caem em desuso, exceto nas academias de ginástica, e toma seu lugar a energia inesgotável fornecida pelas máquinas. Até as técnicas corporais mais elementares como caminhar ou correr recuam consideravelmente e só são solicitadas raramente na vida cotidiana como atividades de compensação da saúde. "Haveria muito a dizer sobre a maneira como o veículo suplanta de certa forma o corpo e o torna anacrônico" (LE BRETON, 2003, p. 20). Próteses técnicas visam reduzir ainda mais o uso de um corpo transformado em vestígio (escadas rolantes, esteiras rolantes). 
Assim, tudo parece paradoxal, ao mesmo tempo em que precisamos cada vez mais do corpo, mais artifícios encontramos para dele não fazer uso. Dessa forma, o dualismo persiste, transformado, alterado, reconfigurado.

\subsection{O corpo em Zygmunt Bauman}

O conceito de corpo para Zigmunt Bauman foi retirado de sua obra "Vida Líquida" (2007), em que afirma na sociedade líquido-moderna é comum o apelo cada vez maior e constante de ofertas de "comidas saudáveis" e pratos requintados, concomitantemente, ao apelo da saúde para o corpo (devemos conceber o corpo). Hoje, temos o conhecimento do que são os corpos e como devemos controlá-los, mas questiona se realmente somos capazes de controlar nosso corpo. Caso este seja, ao invés do corpo uma máquina, como a sociedade atual tenta torná-lo, conforme mencionado por Le Breton (2003), o controle se daria, do contrário, como controlá-lo?

Na sociedade dos produtores, as virtudes do corpo são opostas às virtudes consideradas pela sociedade de consumidores - é claro, os produtores precisam de corpos disformes para que possam seduzir com propagandas para melhorá-los, oferecendo seus produtos. $\mathrm{O}$ corpo, na sociedade dos consumistas, constitui um valor supremo e é fonte de ansiedade eterna. Essa ansiedade é a fonte de lucros para os especialistas em marketing que oferecem a promessa de reduzir ou eliminar essa ansiedade - é a mais durável e confiável fonte de consumo. Bauman (2007, p. 121) afirma que "os mercados de consumo se alimentam da ansiedade dos potencias consumidores, que eles próprios estimulam e fazem o possível para intensificar". O consumismo é a incitação dos desejos que deve ser renovado sempre, pois um desejo satisfeito seria uma catástrofe para o mercado de consumo. Bauman (2007, p. 122) cita como exemplo um consultor de Educação Física que responde ao seu cliente que desejava comer bem, mas era um impulso incompatível com sua cintura: "venha mais vezes à academia para fazer mais exercícios e acelerar o metabolismo". Mais uma vez, o corpo se apresenta como algo a ser controlado.

O corpo tem como qualidade produzir os prazeres que poderá ser capaz de usufruir, e essa qualidade é classificada como "boa forma". Boa forma significa para os consumidores o mesmo que saúde quer dizer para os produtores. Ambos se referem às condições do corpo, mas invocam aspectos diferentes dessa condição. O ideal de "boa forma" torna o corpo receptor e transmissor de sensações, e é definida pela ausência de limites - seu corpo pode estar em excelente forma, mas sempre é possível melhorá-lo (BAUMAN, 2007).

$\mathrm{Na}$ boa forma (diferente da saúde) não é possível dizer: "agora que alcancei posso parar". Não há uma norma de boa forma - nunca termina, o que caracteriza o vício. Não há um padrão para dizer se o atingimos porque "boa forma" se refere às sensações e se eu nunca experimentar não saberei como é.

Então, lutar pela boa forma é não ter descanso. E essa luta, por vezes, pode durar a vida toda, reformula o mundo externo ao corpo como um local perigoso, hostil - qualquer coisa que você coma ou inale (fumaça) que não está no seu cardápio é um perigo! O "fe- 
nômeno da gordura" tem uma fronteira mal mapeada entre o corpo e o mundo externo com perigos atemorizantes e ao mesmo tempo tentações irresistíveis. A gordura corporal representa o pesadelo realizado; representa a ocupação estrangeira, os terroristas.

Essa comparação feita por Bauman (2007) se deve aos sinais eminentemente confusos e muitas vezes contraditórios sofre o efeito "benigno" e "prejudicial" dos vários alimentos oferecidos - referentes à toda gordura que ainda está fora do corpo (qual alimento tem gordura trans?; é bom ou ruim?) e também daquela que já está em nossos tecidos. "Os especialistas advertem sobre os perigos de comer em excesso e a ameaça da dieta exagerada - mas onde se deve traçar a linha entre a norma e o excesso, e quem poderia traçá-la de maneira adequada?" (BAUMAN, 2007, p. 128).

A "guerra cultural do novo século" é a guerra da gordura, ou seja, a luta entre liberdade e segurança. Assim:

A ascensão da questão da gordura segue de perto, e previsivelmente, a promoção do corpo do consumidor à posição de alvo central do marketing, e dos cuidados com o corpo ao status de principal ponto de venda das mercadorias de consumo (BAUMAN, 2007, p. 129-130).

E "aonde é que tudo isso leva o corpo? Ele é agora tão socialmente regulado quanto antes, mudaram apenas as agências reguladoras" (BAUMAN, 2007, p. 131 ). Quem regula é o mercado consumidor e quem está à margem da sociedade consumista é excluído pelo Estado, são fracassados que podem voltar a ser admitidos na sociedade.

\section{EdUCAÇÃo FíSICA NO ENSINO MÉdIO: O CORPO COMO ATOR PRINCIPAL}

Após nos apoiarmos em Le Breton e Bauman para contextualizar a ideia de corpo na contemporaneidade, indagamos: o que a Educação Física escolar tem a ver com tudo isso? A resposta nos parece óbvia, já que estamos inseridos em sociedade de consumo, líquido-moderna, em que estão inseridas nossas escolas e nossos alunos, mas, não tão óbvia assim diante de questões que assolam o dia a dia dos jovens (nossos alunos!) e que nem sempre são discutidas pela escola. Questões essas que perpassam desde o corpo para o consumo, com as cirurgias estéticas, o uso de suplementos alimentares e esteroides anabolizantes, até as dietas inadequadas, transtornos alimentares e obesidade.

Partindo da premissa que a Educação Física escolar tem como um de seus objetivos: oportunizar/vivenciar manifestações culturais construídas historicamente e valorizadas pela nossa sociedade há longa data, de modo que, ao aprendê-las, ganhem autonomia para praticá-las por toda a vida, nos mais diferentes ambientes em que estas se manifestarem e para que vivam melhor individualmente e em sociedade (SANTANA; REIS, 2006), apresentaremos algumas contribuições do que/como tematizar questões abordadas pelos autores sobre o corpo na atualidade nas aulas de Educação Física escolar do ensino médio. As sugestões apresentadas partem de práticas pedagógicas concretizadas no ensino médio do 
curso técnico em agropecuária do Instituto Federal de Educação, Ciência e Tecnologia de Mato Grosso (IFMT), campus São Vicente.

As subdivisões apresentadas são meramente didáticas, pois as temáticas propostas tratam de conteúdos que podem dialogar entre si e certamente com outros assuntos não tratados neste texto. Em tempo, vale destacar que as propostas que seguem podem ser desenvolvidas no decorrer de um bloco ou sequência de aulas e não numa única aula.

\subsection{O corpo e a estética}

O corpo e a saúde estão diretamente ligados à busca de um corpo perfeito e que a obtenção de um (saúde) pode levar, positiva ou negativamente à aquisição do outro (estética) ou vice-versa. A estética se referencia principalmente pela imagem corporal, que para Le Breton (2012), é a representação que o sujeito faz de seu corpo, a maneira pela qual ele parece mais ou menos consciente, a partir de um contexto social e cultural particularizado por sua história pessoal.

Para Le Breton (2012), a imagem do corpo reflete por sua forma, conteúdo, um saber (conhecimento) e um valor. A forma se refere ao:

[...] "sentimento da unidade das diferentes partes do corpo, de sua apreensão como um todo, de seus limites precisos no espaço, e de um conteúdo: isto é, a imagem de seu corpo como um universo coerente e familiar no qual se inscrevem sensações previsíveis e reconhecíveis". (...) o conhecimento, pelo sujeito, ainda que rudimentar, da ideia que a sociedade se faz da espessura invisível do corpo, saber de que ele é constituído, como se agenciam os órgãos e as funções, esses três eixos acompanham o homem ao longo de sua existência e remodelam-se segundo a medida dos eventos" (LE BRETON, 2012, p. 231).

A imagem do corpo é aqui uma medida familiar de sua relação com o mundo, e não existe, em princípio, conflito entre a realidade cotidiana do sujeito e a imagem que ele tem de seu corpo. Já o quarto componente - VALOR - é para o sujeito a interiorização do juízo social que cerca os atributos físicos que o caracterizam (bonito/feio, jovem/velho etc.). Segundo sua história pessoal e classe social, ele faz um juízo de si que marca com sua impressão a imagem que ele faz de seu corpo e a estima que ele tem por si. O juízo de VALOR é que registra o ponto de vista do outro e força o sujeito a se ver sob um ângulo mais ou menos favorável (PANKOW apud LE BRETON, 2012).

A estética, quando não ultrapassa os limites da saúde, pode trazer benefícios para o indivíduo, como a elevação da autoestima e, por conseguinte, a melhora de sua qualidade de vida - exercícios, alimentação saudável, entre outros. O que podemos propor em nossas aulas de Educação Física? Inúmeras são as possibilidades, mas vejamos uma proposta com base nos "Transtornos Alimentares".

Inicialmente, podemos instaurar um debate sobre o que é "corpo perfeito" para os alunos. Depois, solicitar que assistam a programas de televisão, principalmente os de auditório (onde há plateia) e identificar quais corpos estão presentes ali. Será que são os mesmos

Comunicações | Piracicaba | v. $25 \mid$ n. $3 \mid$ p. 325-339| set.-dez. 2018 
padrões presentes na rua, ponto de ônibus ou escola? Após a realização dessa pesquisa, discutir com os alunos as impressões que retiraram da pesquisa solicitada e propor discussões sobre a influência da mídia nos padrões estéticos atuais. Nesse momento, é possível exibir aos alunos pequenos textos, reportagens, imagens que indiquem, por exemplo, representações de formas opulentas do corpo feminino no decorrer da história, ou ainda, as campanhas publicitárias de academias, que por vezes, ferem a autoestima das pessoas, reafirmando padrões estabelecidos socialmente.

Outra possibilidade de discussão sobre corpo e estética é apresentar os conceitos dos transtornos alimentares, Anorexia, Bulimia e Vigorexia e, posteriormente, identificar se os alunos já tiveram contato com pessoas que mostraram algum desses transtornos. Diversos

vídeos podem ser obtidos na internet que apresentam/debatem o assunto. É importante mostrar aos alunos os vários pontos de vista a respeito do tema, já que é explícito a culpabilização da mídia pela busca do corpo perfeito das jovens, que se espelham nos corpos magros e ou/malhados estampados em revistas e programas de televisão. Porém, para Le Breton (2009), a Anorexia e Bulimia são consideradas condutas de risco que levam os jovens a pôr em perigo a própria vida, sendo os motivos inúmeros e apenas a história pessoal de cada um que pode esclarecer os sentidos da passagem ao ato. As "condutas de risco" aplicadas aos jovens designam uma série de atitudes díspares, que vão desde a exposição de si mesmo com probabilidade de se ferir ou morrer, perigo à sua saúde, mas às vezes é discreta e silenciosa (adesão a uma seita - demissão identitária); podem ter origem no abandono, na indiferença familiar, mas também, ao contrário, na superproteção, especialmente materna, sendo esta uma das explicações para a Anorexia. Assim, a anorexia é um jogo exemplar de vertigem. O apetite é uma afetividade em ação. Se os distúrbios alimentares constituem uma alteração do gosto de viver, são também uma recusa do vínculo que está na base da relação mãe-filho: a nutrição. A anoréxica procura se desligar de todas as referências ao corpo de sua mãe.

Para finalizar, podemos solicitar aos alunos que façam uma breve pesquisa em mídia impressa e digital para, posteriormente, realizar uma mostra sobre o assunto, de maneira a expor a temática aos alunos do ensino fundamental, por exemplo, introduzindo assim o assunto. Em tempo, abordar a temática dos transtornos alimentares permite relacioná-la com a alimentação saudável, suplementação alimentar e até mesmo o doping.

\subsection{O corpo e a saúde}

Uma possibilidade de ação, por exemplo, no $1^{\circ}$. ano do ensino médio, é abordar/tematizar os conhecimentos sobre o corpo a partir das seguintes temáticas: nutrição esportiva e suplementar; saúde e estética (transtornos alimentares: anorexia, bulimia, vigorexia e obesidade); sedentarismo; efeitos fisiológicos do exercício (benefícios da atividade física, frequência cardíaca, oxigenação e aumento de massa muscular).

Para tanto, numa aula sobre saúde podemos apresentar e discutir a diferença conceitual entre Atividade Física e Exercício Físico; explanar e discutir os benefícios do exercício 
físico, bem como, seus efeitos fisiológicos no organismo, adotando, por exemplo, recursos audiovisuais que mostrem esses benefícios, o que pode ser facilmente obtido na internet; diferenciar exercício aeróbio de anaeróbio.

Após a exposição, podemos conduzir os alunos a um espaço amplo, quadra, campo, salão, com vistas a verificar os efeitos fisiológicos do exercício aeróbio, a partir de atividades de longa duração, como caminhar ao redor do campo, participar de um jogo de queimada ou até mesmo uma sequência de brincadeiras populares como variações do pega-pega. Por sua vez, a proposição de vivência de exercício anaeróbio pode ser a participação em atividades num circuito de exercícios funcionais de curta duração e alta intensidade.

Após a prática é necessário discutir com os alunos as alterações fisiológicas que "sentiram", tanto na vivência de um exercício aeróbio quanto anaeróbio, bem como, correlacioná-los com os conceitos apreendidos.

Ao finalizar esta sequência, podemos, ainda no campo dos conhecimentos sobre o corpo, debater questões a respeito da obesidade e sedentarismo que estão ligadas tanto à saúde quanto à estética.

Sugerimos debater os conceitos de estilo de vida saudável e qualidade de vida, comparando, por exemplo, o que se faz e/ou se pode fazer em locais em que temos acesso fácil às tecnologias e à vida urbana e o que é possível realizar em regiões do campo, onde as restrições são maiores. Propomos ainda, uma vivência de experiências motoras simples que os alunos não tiveram na infância e dialogar com a qualidade de vida que eles têm hoje e que tiveram na infância. Posteriormente, podemos apresentar o conceito de sedentarismo, demonstrando que o mesmo é uma das principais causas da obesidade, exibindo, para exemplificar, o vídeo "Manter a forma pode salvar você!" (2015), que remete ao tempo dos homens da caverna, período denominado de pré-história, em que três indivíduos tentam fugir de dinossauros e para tanto sobem em árvores bem altas e finas; um deles é obeso, provavelmente sedentário e ainda carrega consigo um sanduíche e refrigerante, e quando sobe na árvore, ela entorta com o seu peso e é devorado pelos animais. Esse vídeo é uma via de acesso para discutirmos o conceito de obesidade, que muito mais do que estética, é considerada um problema de saúde pública tão preocupante quanto a desnutrição.

A partir do conceito de obesidade e suas principais causas, podemos apresentar o IMC (Índice de Massa Corporal) aos alunos, ensinar a calculá-lo e utilizá-lo como referência para o controle da obesidade, lembrando que este é apenas um dos recursos existentes para a avaliação da massa corporal, além de propor que os alunos pesquisem junto aos colegas e servidores da escola seus respectivos pesos e alturas (a fim de calcular o IMC), se é sedentário ou pratica exercícios físicos, entre outras questões que poderão ser elaboradas com os alunos.

Outra proposta interessante é sugerir que os alunos assistam ao documentário "Super Size Me: a dieta do palhaço" (2004), que apresenta a história de um homem que durante um mês se alimenta apenas com comidas do tipo fast food e reduz drasticamente atividade física, introduzindo o debate de questões relacionadas à nutrição e alimentação rica em gorduras. 
O documentário possibilita um diálogo com as ideias propostas por Bauman (2007) sobre a guerra que estabelecemos contra o terrorismo da gordura, tendo duas frentes que se opõem: uma é representada pelos advogados especialistas (representam as vítimas) em defender pessoas ignorantes enganadas pelas empresas produtoras de alimentos (comem demais seduzidos pelos prazeres oferecidos depois entram na justiça por terem engordado); outra pelos grandes produtores de alimentos (fast foods) que se apoiam nos direitos constitucionais do cidadão e da liberdade de escolha do consumidor (liberdade de comer transformada em liberdade individual). Afinal de contas, quem deveria mudar as atitudes e ter (ou oferecer) uma vida mais saudável: a empresa ou você?

Entendemos que falar de um corpo saudável é remetermos ao corpo não saudável. E a partir daí diversas frentes poderiam ser exploradas, como a estética que pode levar ao corpo não saudável, ou o esporte que não pode ser considerado sinônimo de saúde, visto a busca constante de transcender limites e chegar ao lugar mais alto a qualquer custo (doping).

\subsection{O corpo e a nutrição}

Para Le Breton (2012, p. 252), "mudar o corpo para mudar a vida" é um belo exemplo da banalização atual do discurso dualista, em que a gestão do próprio corpo significa o mesmo que uma máquina da qual é preciso tirar o máximo rendimento.

\footnotetext{
A dietética, com efeito, é outra faceta dessa intervenção plástica em si, que conhece hoje um sucesso crescente a partir da multiplicação das revistas que difundem seus produtos: orientação da alimentação segundo imperativos da "forma", busca de uma racionalidade que modifica os dados simbólicos ligados à refeição, referências a novos valores através dos produtos "bio", etc. (LE BRETON, 2012, p. 253).
}

Relembrando os conceitos apresentados por Bauman (2007) no tópico 2.2, o corpo é socialmente regulado pelo mercado consumidor, sendo cada vez mais difícil encontrar o ponto de equilíbrio entre a alimentação adequada, a grande oferta e facilidade dos fast foods e a ameaça da dieta exagerada.

Abordar a temática da nutrição nos permite não apenas debater sobre o que é uma alimentação saudável versus uma dieta inadequada, mas também levar os alunos a refletirem sobre o círculo vicioso que preconiza a sociedade de consumo: ter um corpo perfeito/malhado, pagar para fazer exercícios, consumir produtos nutricionais que suplementarão a alimentação e garantirão o corpo perfeito, entre outros. A partir deste assunto, tanto podemos aproveitar temáticas, textos e filmes, como podemos convidar um profissional especialista no assunto para uma palestra, como um nutricionista.

Num segundo momento, podemos propor a construção de peças teatrais sobre o tema da Nutrição Básica e estabelecer um trabalho interdisciplinar com a Língua Portuguesa e Literatura, cabendo a esse componente curricular oferecer aos alunos modelos de textos teatrais, trabalhando com os principais elementos que constituem o gênero texto teatral 
escrito (enredos, diálogos, cenários, rubricas etc.), bem como, uma pequena apresentação e posterior discussão a respeito de que elementos da atuação fizeram dela inteligível e agradável e em que poderia ser melhor enquanto recursos técnicos de voz e expressão corporal. Nesse caso, o teatro se apresenta como conteúdo de ensino de Língua Portuguesa e Literatura e procedimento metodológico para ensinar Nutrição Básica em Educação Física. Para debatermos a "Nutrição Básica", podemos abordar o que são e para que servem "Carboidratos", "Proteínas", "Vitaminas" e "Gorduras", tanto com a exposição direta dessa temática pelo professor, como por vídeos, ilustrações e outros tipos de apresentação.

\subsection{O corpo e o "esporte"}

Sobre o esporte, podemos estabelecer uma estreita relação com o conceito de "Vida líquida" apresentado por Bauman (2007), sendo essa a forma de vida que tende a ser levada à frente numa sociedade líquido-moderna (outro importante conceito de Bauman) que, por sua vez, é uma sociedade em que as condições sob as quais agem seus membros mudam num tempo mais curto do que aquele necessário para a sua consolidação, em hábitos e rotinas, as formas de agir. A vida líquida não pode manter a forma ou permanecer em seu curso por muito tempo. As realizações individuais não podem solidificar-se em posses permanentes. Prever tendências futuras a partir de eventos passados torna-se cada dia mais arriscado e com frequência enganoso. É uma vida precária, vivida em condições de incerteza constante. A prioridade no mundo líquido-moderno é "livrar-se das coisas", sendo assim a indústria da remoção de lixo é destaque na economia, pois "a sobrevivência dessa sociedade e o bem-estar de seus membros dependem da rapidez com que seus produtos são enviados aos depósitos de lixo e da velocidade e eficiência da remoção de detritos" (BAUMAN, 2007, p. 9). Somos contaminados pelo apelo de "abrir mão de tudo" em busca de uma melhor qualidade de vida, sendo que nem alcançamos o "tudo" ainda, aliás, o que se entende por tudo na sociedade líquida? O lema é modernizar-se ou perecer! Nesta vida de consumo, os objetos perdem a utilidade enquanto são usados e "ser adequado para o consumo" é a única característica que define a sua função.

Após apresentar o conceito de sociedade de consumo a partir das ideias de Bauman e levar os alunos a refletirem sobre a sociedade em que vivem, é possível produzir uma relação com o conteúdo futebol, estabelecendo uma relação com o consumismo, que é muito forte nessa modalidade esportiva, além do grande apelo midiático. É possível, nesse momento, relacionar o futebol com a sociedade de consumo que vivemos.

Podemos abordar o uso do doping e/ou da simulação de faltas pela via da discussão da “Ética no Esporte". Nesse sentido, é possível apresentar o conceito de Ética (e até trabalhar interdisciplinarmente com Filosofia, por exemplo). Propomos ainda a realização de um debate em formato de júri popular para avaliar acontecimentos no esporte, como racismo, homossexualismo, gênero, a partir de reportagens em sites especializados na modalidade, que produzem muita informação acerca do assunto e são de fácil acesso.

Outra vertente que pode ser abordada na relação o corpo e o esporte é a possibilidade 
de os alunos vivenciarem diferentes formas de organização esportiva e selecionar uma modalidade para que os mesmos organizem e vivenciem um torneio esportivo. Na mesma ação, solicitar aos alunos que anotem situações observadas durante a execução do torneio que considerem antiéticas para posterior discussão em aula. E discutir essas situações explanadas pelos alunos sobre o torneio.

Para Le Breton (2003), diante da confusão das referências e da incerteza que reina a respeito do futuro, hoje os indivíduos replicam por uma produção pessoal de sua identidade de um modo mais individualista por meio de uma espécie de bricolagem cultural, na qual as influências sociais procedem mais da atmosfera do momento do que de regularidades mais profundas e duráveis. O indivíduo (e também o atleta) tende a ter a si próprio por referência. $\mathrm{O}$ imaginário que preside ao seu uso torna os psicotrópicos um dos meios simbolicamente eficazes de produzir sua identidade pessoal de um modo que dê segurança pela busca de um estado psicológico adaptado às condições de vida: o indivíduo adapta sua vigilância ou sua resistência com o auxílio de estimulantes psíquicos ou de fortificantes, ou combate do estresse tomando tranquilizantes ou soníferos para acalmar suas tensões. Da mesma forma, o atleta de alto rendimento faz uso de substâncias proibidas para garantir um melhor desempenho e, por conseguinte, o prestígio e identidade pessoal.

A partir do slogan "Esporte é saúde", propomos discussões sobre o esporte de alto rendimento e sua relação com a saúde, focando o doping como um recurso utilizado pelos atletas, que não proporciona saúde e o uso é considerado uma atitude antiética. É possível, ainda, apresentar a lista de substâncias e métodos proibidos pelo Código Mundial Antidopagem, que é atualizada a cada início de ano. Nessa lista, há o grupo de substâncias proibidas denominado de "Agentes Anabólicos" que incluem os esteroides anabolizantes. É interessante fazer um parêntese nesse grupo para distingui-lo dos "suplementos alimentares", comumente confundidos com os anabolizantes e, facilmente encontrados no universo das academias, locais muitas vezes frequentados pelos jovens de ensino médio.

Por fim, podemos visitar uma academia de musculação para que os alunos conversem com os frequentadores do local para saber a opinião dos mesmos sobre o uso de anabolizantes, se conhecem seus efeitos colaterais, se fazem uso de algum suplemento, entre outros questionamentos. Após, essa pesquisa, o assunto deve ser debatido em sala novamente, retomando as ideias de Le Breton (2003) em que ressalta os modos voluntários de fabricação de si, de modelagem da identidade pessoal, que se revela também em outras práticas sociais: o uso corrente de vitaminas, fortificantes, dietética, modelagem da forma do corpo, ginástica tonificantes, aeróbica, regimes alimentares, cujo sucesso também se conhece hoje em dia.

\section{Considerações finais}

A partir das discussões sobre saúde, estética, nutrição e esporte e suas relações com o corpo, é possível perceber como os conceitos propostos por Le Breton $(2003 ; 2012)$ e 
Bauman (2007) estão presentes, podem e devem ser discutidos nas aulas de Educação Física. É possível que, durante as aulas de Educação Física no ensino médio, conforme o exposto, façamos que o aluno reflita a respeito das características da sociedade em que vivemos hoje, que afetam sua relação com o corpo, ou seja, o corpo que se transforma cada vez mais em máquina, um objeto imperfeito, um rascunho a ser corrigido, que precisa se transformar fisicamente para solucionar problemas de outra ordem, que requer orientações diversas para se manter em "forma", o que incita no indivíduo o consumismo que nunca acaba, que nunca se satisfaz.

As possibilidades de tematizar o corpo nas aulas de Educação Física do ensino médio sugeridas ilustram como o contexto escolar pode se apropriar dessas discussões e conhecimentos, conduzindo os alunos a outras reflexões e análises, de maneira crítica e consciente.

\section{REFERÊNCIAS}

BAUMAN, Zygmunt. Vida líquida. Rio de Janeiro: Jorge Zahar, 2007.

. Identidade. Rio de Janeiro: Jorge Zahar, 2005.

FENSTERSEIFER, Paulo Evaldo; GONZÁLEZ, Fernando Jaime. Desafios da legitimação da educação física na escola republicana. Horizontes. Dourados, MS, n. 2, v. 1, jul./dez. 2013.

GONZÁLEZ, Fernando Jaime; FENSTERSEIFER, Paulo Evaldo. Entre o "não mais" e o "ainda não": pensando saídas do não-lugar da EF escolar I. In: Cadernos de Formação RBCE. Campinas, SP: CBCE e Autores Associados, v. 1, n. 1, 2009, p. 9-24.

LE BRETON, David. Adeus ao corpo: antropologia e sociedade. Campinas, SP: Papirus, 2003.

. Condutas de risco: dos jogos de morte aos jogos de viver. Campinas, SP: Autores Associados, 2009.

Antropologia do corpo e modernidade. Petrópolis, RJ: Vozes, 2012.

MOREIRA, Evando Carlos; GRUNENNVALDT, José Tarcísio. Contra a idealização da educação física e a favor de sua prática social: porque o conceito e a identidade da educação física são construídos na escola. In: ANJOS, José Luiz dos; ALMEIDA, Felipe Quintão de (Orgs.). Educação física, corpo e tradição: o jogo das comunidades tradicionais. Curitiba, PR: Appris, 2016, p. 59-80. 
NEIRA, Marcos Garcia. Ensino de educação física. São Paulo: Thomson Learning, 2007.

. O ensino da educação física na educação básica: o currículo na perspectiva cultural. In: MOREIRA, Evando Carlos (Org.). Educação Física escolar: desafios e propostas 1. 2. ed. Jundiaí, SP: Fontoura, 2009, p. 65-94.

SANTANA, Wilton Carlos; REIS, Heloísa Helena Baldy. A pedagogia do esporte e o desafio de educar para a autonomia. In: MOREIRA, Evando Carlos (Org.). Educação física escolar: desafios e propostas 2. Jundiaí, SP: Fontoura, 2006, p. 133-152.

SUPER Size Me: A Dieta do Palhaço. Direção de Morgan Spurlock. Produção de Morgan Spurlock. Estados Unidos: Imagem Filmes, 2004 (96 min.), DVD, son., color. Legendado.

MANTER a forma pode salvar você! 2015. Son., color. Legendado. Disponível em: https:// www.youtube.com/watch?v=seHdEkn86mE. Acesso em: 28 jul. 2015.

\section{Larissa Beraldo KaWashima}

Doutorando em Educação - Universidade Federal de Mato Grosso. Mestre em Educação - Universidade Federal de Mato Grosso. Professora do Instituto Federal de Educação, Ciência e Tecnologia de Mato Grosso, Cuiabá, MT, Brasil. Email: lalabeka@hotmail.com

\section{Evando Carlos Moreira}

Pós-doutor em Estudos da Criança - Universidade do Minho. Doutor e Mestre em Educação Física - Universidade Estadual de Campinas. Professor da Universidade Federal de Mato Grosso, Cuiabá, MT, Brasil. Email: ecmmoreira@uol.com.bt

Submetido em:13-3-2017

Aceito em:13-8-2018 